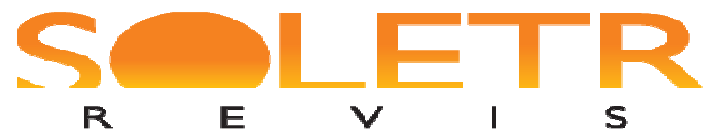

$\mathbf{R}$

$\mathbf{E}$
T

A N. 24-2012.2-MANOEL MARTINS DE SANTANA FILHO

\title{
Conhecendo espacialidades com Carlos Drummond de Andrade ${ }^{1}$
}

\author{
Manoel Martins de Santana Filho ${ }^{2}$
}

\begin{abstract}
Resumo: Este artigo apresenta uma experiência que revela o potencial e as possibilidades fecundas que nascem do diálogo da Geografia com a literatura. Diálogo que promove leitura, cognição e representação sobre o mundo e sua geograficidade. A partir da produção de Carlos Drummond de Andrade exploram-se algumas dessas veredas que revelam a geografia do texto literário e a literatura inspirando-se em dada geografia. A leitura desses textos exemplificados na experiência relatada apresenta-nos algumas visões da experiência humana sobre o cotidiano, sobre a memória, sobre a vida urbana e rural, sobre a história, a memória e a cultura. Por fim, pretende-se que este diálogo geoliterário promova uma educação geográfica que possibilite aos estudantes e ao homem contemporâneo desenvolver sua condição de autoria e expressão.
\end{abstract}

Palavras-chave: Geografia. Literatura. Educação geográfica. Carlos Drummond de Andrade.

\section{Introdução}

É um desafio apresentar um estudo ou fazer uma intervenção interessante para especialistas quando o que temos trata-se de algumas incursões no campo desse diálogo com a literatura, a partir da condição de leitor e geógrafo. Na condição de geógrafo-educador, a experiência de ler e interessar-se pelo texto drummondiano, acompanhado pela vivência de outros profissionais - com o objetivo de desenvolver um projeto que resgata a memória e incentiva a leitura e a descoberta da crônica e da poesia de Carlos Drummond de Andrade amplificou em muito as possibilidades desse diálogo. O presente texto tem esse trabalho como inspiração - a inteireza da história literária de Drummond com seu testemunho da história, "da Experiência Humana".

A leitura das crônicas de Carlos Drummond de Andrade apresenta-nos algumas visões da experiência humana sobre o cotidiano, sobre a memória, sobre a vida urbana e rural, sobre a história, a memória e a cultura. Tal leitura possui elevado potencial formativo para além das

\footnotetext{
${ }^{1} \mathrm{O}$ artigo é o registro de uma palestra pronunciada no III Seminário de Estudos Literários do Programa de PósGraduação em Estudos Literários da Faculdade de Formação de Professores da UERJ, nos dias 23 e 24 de outubro de 2012.

${ }^{2}$ Geógrafo-educador pela UFF, com Mestrado em Educação pela UERJ e doutorado em Geografia pela USP. Atualmente é docente e diretor da Faculdade de Formação de Professores da Universidade do Estado do Rio de Janeiro, Município de São Gonçalo, onde trabalha com Didática e Metodologia da Geografia. Desenvolve grupos de pesquisa sobre os temas: Didática e Epistemologia da Geografia e mantém Grupo de Estudo sobre Geografia e Literatura.
} 

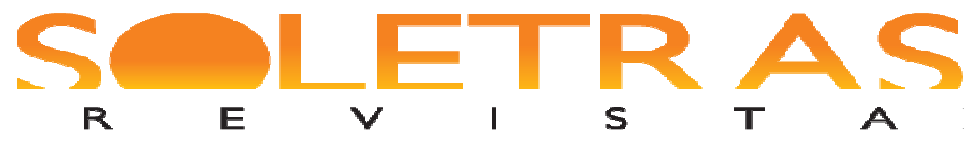

atividades escolares. Contudo, reconhecemos que a formação de leitores recebe uma contribuição fundamental da educação escolar e, também nesse aspecto, vimos acumulando alguma experiência como educador na educação básica e na formação de professores. Consideremos esses elementos como guias do diálogo aqui proposto.

\section{O grupo de estudos geografia e literatura na FFP}

As aproximações e encontros da Geografia com a Literatura tem-se tornado campo promissor de pesquisa e diálogo, mas, sobretudo de compreensão mais aberta, mais ampla, sobre a percepção e representação que construímos sobre nós, produtores que somos de paisagens e geografias múltiplas e complexas. No trabalho de formação de professores de Geografia desenvolvido na Faculdade de Formação de Professores da UERJ, em São Gonçalo, temos enfrentado esse desafio com a organização de um grupo de estudos e pesquisa sobre os diálogos geoliterários e oferecendo componente curricular eletivo com o mesmo tema. Nessa experiência, algumas atividades revelaram-se fecundas, ampliando as articulações possíveis para a compreensão da geografia do mundo, bem como das possibilidades educativas. Dois exemplos: a leitura dos versos de Patativa do Assaré ${ }^{3}$ e seu modo de apresentar o Sertão, explorados em oficinas de leitura, apontando-nos uma forma própria de enunciar a palavra sobre aquela paisagem partindo da perspectiva do sertanejo não é difícil reconhecer como tal discurso nem sempre aparece nas atividades escolares; também com a leitura de obras de Frederico Garcia Lorca e João Cabral de Mello Neto, em cujos textos acompanhamos no rio, objeto geográfico, trajetória de vida e de transformações foi possível pensarmos um paralelo entre o texto literário e a geograficidade expressa na vida dos homens e seus lugares.

Brasil afora, muitos pesquisadores vem construindo interessantes experiências de leitura e pesquisa desse diálogo entre a geografia e a literatura, especialmente em São Paulo, Rio de

\footnotetext{
${ }^{3}$ Antônio Gonçalves da Silva (05/03/1909 - † 08/07/2002), o Patativa do Assaré. Frequentou a escola por alguns meses, em 1921, mas desde então vem "lidando com as letras", como ele mesmo afirmou. Agricultor, em 1922 já atuava como versejador em festas, e a partir de 1925, quando comprou uma viola, deu início à atividade de compositor, cantor e improvisador. Em 1926 teve um poema publicado no Correio do Ceará, mas seu primeiro livro, Inspiração Nordestina, seria lançado trinta anos depois, em 1956. Em 1978 publicou o livro Cante Lá que Eu Canto Cá, e em 1979 iniciou, com Poemas e Canções, a gravação de uma série de discos, entre os quais se destacam Canto Nordestino (1989) e 88 Anos de Poesia (1997). Seu último livro, Cordéis-Patativa do Assaré , é de 1999. A poesia de Patativa, que verseja em redondilhas e decassílabos, traduz uma visão de mundo "cabocla", muitas vezes nostálgica e desapontada com as mudanças trazidas pela modernidade e pela vida urbana. Sua obra aborda os valores e os ideais dos camponeses do interior do Ceará, em poemas que tematizam da reforma agrária ao cotidiano dos sertanejos cearenses.
} 

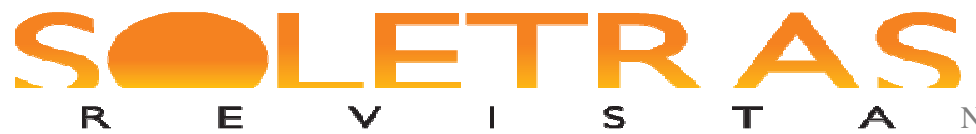

Janeiro e Bahia fazendo desse campo de interesse uma experiência viável de aprofundamento para o diálogo geoliterário no Brasil.

\section{A experiência de dialogar com o texto do Carlos Drummond de Andrade}

A aproximação e acesso ao acervo de crônicas e poesias de Drummond ${ }^{4}$ permitiu-nos superar a condição de leitor do Drummond (longe de ser especialista) e de professor, para conhecer mais de perto seus textos, seus arquivos, mergulhar nas suas palavras e vislumbrar, pelas janelas oferecidas por elas, mensagens, testemunhos e sensibilidade. A contribuição formativa e educacional no horizonte desse trabalho exigia alguns cuidados e a atenção para os elementos que pudessem ser mais significativos no resgate da memória apontassem para possibilidades de novos textos e autoria.

Algumas ideias nortearam o diálogo, depois de conceber a proposta de apresentar o Drummond como testemunho da experiência humana, por conta de sua vivência ao longo de quase todo o Século XX - 1902 a 1987. Destacamos algumas dessas ideias acompanhadas de um exemplo:

(a) Em sua trajetória, um olhar aguçado e uma sensibilidade para a vida, em perspectivas um pouco deslocadas do trivial. O anjo torto gauche na vida!

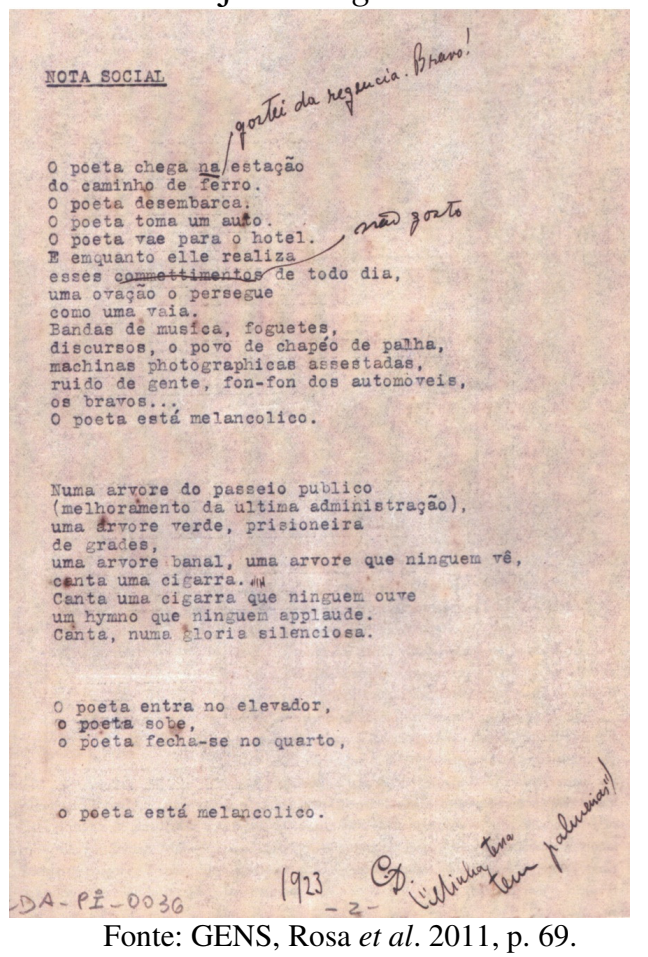

\footnotetext{
${ }^{4}$ Experiência vivida na produção de um material pedagógico para o Projeto Memória, da Fundação Cultura Banco do Brasil, na equipe formada na Fundação Casa de Rui Barbosa, no Rio de Janeiro. Este material está disponível em: http://www.projetomemoria.art.br.
} 


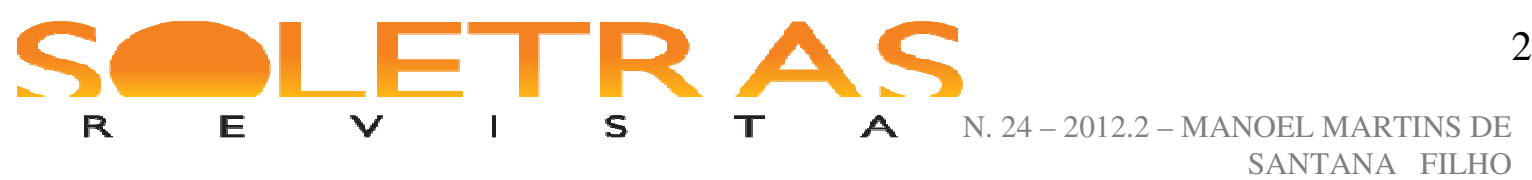

\section{Poema de Sete Faces}

Quando nasci, um anjo torto desses que vivem na sombra disse: Vai, Carlos! ser gauche na vida.

As casas espiam os homens que correm atrás das mulheres.

A tarde talvez fosse azul, não houvesse tantos desejos.

$\mathrm{O}$ bonde passa cheio de pernas:

pernas brancas pretas amarelas.

Para que tanta perna, meu Deus, pergunta meu coração.

Porém meus olhos não se perguntam nada.

O homem atrás do bigode é sério, simples e forte.

Quase não conversa.

Tem poucos, raros amigos o homem atrás dos óculos e do bigode.

Meu Deus, por que me abandonaste se sabias que eu não era Deus se sabias que eu era fraco.

Mundo mundo vasto mundo se eu me chamasse Raimundo seria uma rima, não seria uma solução.

Mundo mundo vasto mundo mais vasto é meu coração.

Eu não devia te dizer mas essa lua mas esse conhaque botam a gente comovida como o diabo.

Podemos refletir sobre isso nos versos do Poema de Sete Faces (Alguma Poesia, 1930) ou em Nota Social ${ }^{6}$, do mesmo livro. Em ambos os textos nota-se um posicionamento sobre o mundo, sobre as ações cotidianas citadas com ironia e sensibilidade, as trajetórias e caminhos: o posicionamento alude à expressão de uma geografia que se faz vida ou vida que se faz geografia.

(b) Explorar a ideia da janela a partir da qual o cronista olhava o mundo - "o observador do escritório". Sua atenção aos fluxos urbanos, das pessoas, do tempo. São registros muito interessantes constatados em algumas dessas crônicas. Nesses registros a vida na paisagem transparece.

\footnotetext{
${ }^{5}$ Retirado da edição fac-similar organizada por Ferraz (2010), edição comemorativa dos 80 anos de aniversário da primeira publicação.

${ }^{6}$ Ver em Ferraz (2010).
} 


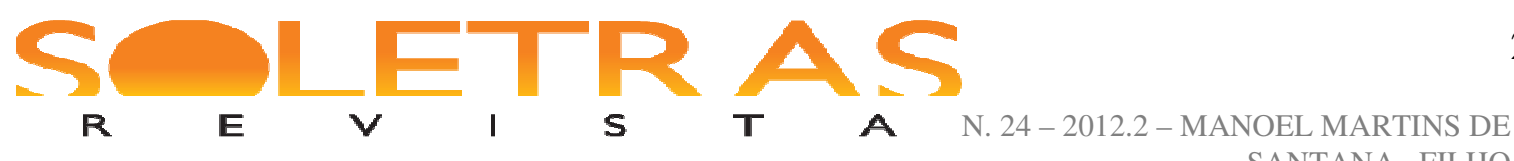

Como ilustração dessa ideia, encontramos o poema em prosa "O operário no mar", no livro Sentimento do Mundo, de 1940, e a crônica "Imagens do Rio":

Na rua passa um operário. Como vai firme! Não tem blusa. No conto, no drama, no discurso político, a dor do operário está na blusa azul, de pano grosso, nas mãos grossas, nos pés enormes, nos desconfortos enormes. Esse é um homem comum, apenas mais escuro que os outros, e com uma significação estranha no corpo, que carrega desígnios e segredos. [...] Teria vergonha de chamá-lo meu irmão. Ele sabe que não é, nunca foi meu irmão, que não nos entendemos nunca. E me despreza...Ou talvez seja eu próprio que me despreze a seus olhos. [...] Agora está à caminho no mar. Eu pensava que isso fosse privilégio de alguns santos e navios. Mas não há nenhuma santidade no operário, e não vejo rodas nem hélices no seu corpo, aparentemente banal. Sinto que o mar se acovardou e deixou-o passar. Onde estão nossos exércitos que não impediram o milagre? [...].

\section{Imagens do Rio}

A Pipa

A Rua Joaquim Nabuco, no Posto 6, é uma rua feliz: há nãos que não se queixa de falta d'água.

Não que disponha de grandes nascentes, adutoras ou reservatórios: dispõe do mar e de Deus. E se os moradores não se queixam, isto não se deve a uma delicada constituição psicológica. Chegaram à conclusão de que não adianta queixar-se. Seria maltratar um tempo de ouro, que melhor de emprega na pesquisa e na expectação da pipa.

A pipa é uma instituição moderna disposta sobre pneus, e que dá ou promete água. É sobretudo um sonho, uma alegoria motorizada, e a suprema aspiração do vivente. [...]

Se não chegou, azar o seu; saia à sua procura. A qualquer momento do dia ou da noite, há sempre um carro-pipa nas ruas da zona sul, demonstrando ao mesmo tempo a falta d'água e a existência dela. [...]

Chegou? Realmente uma algazarra festiva se levanta em frente ao seu lar. É a pipa! Às vezes as mangueiras são curtas, não atingem a caixa-d'água. Não importa. Alguém na Prefeitura pensou em você, embora com equipamento insuficiente. Outras vezes, é a própria água que falta à própria pipa d'água, como se faltassem lençóis ao Copacabana Palace, incenso à Candelária, dinheiro ao Banco do Brasil. Não importa. Chega um momento em que você ouve o ronco tenebroso do motor enchendo de água sua casa, e embora um pouco demais, porque o jato inunda as paredes e as pessoas, você sabe que há no mundo, uma coisa chamada água, embora barrenta; que ela pode chegar ao seu domicílio, embora jamais pela torneira. Gratifique então os honrados homens da pipa com 50 cruzeiros: é o bastante, embora o dr. Café Filho dê 100.

Estudaremos a sociologia da pipa.

Carlos Drummond de Andrade, Jornal do Brasil, 09 de janeiro de 1954. 


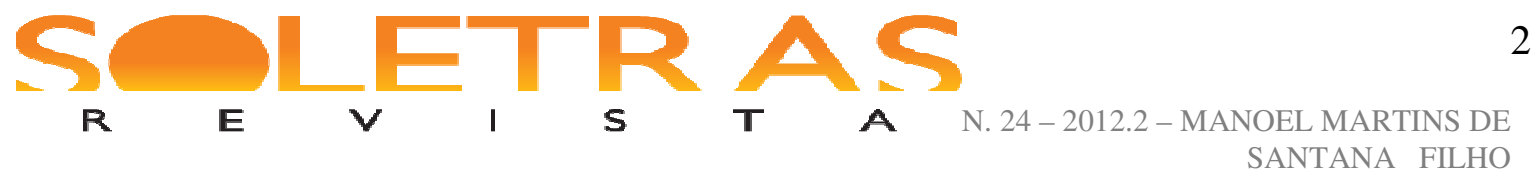

Em uma crônica intitulada "A Pipa", Drummond também brinca, em sua fina observação e ironia, com uma questão cotidiana urgente no bairro carioca onde viveu tantos anos, Copacabana (Rio de Janeiro) - a falta d'água. Em alguns trechos o cronista exalta com reconhecida ironia a existência da pipa d'água como "o sonho, a alegoria motorizada"; em outros, o quanto o evento da pipa favorece a aproximação entre as pessoas, distanciadas que se encontram no ambiente da cidade.

(c) Drummond antecipou questões socioambientais fundamentais em suas crônicas, quando tratou do ambiente urbano, sobre as moradias na cidade, a exploração dos recursos minerais, seu olhar sobre/contra a guerra etc.

Na crônica Mané e Sonho (Jornal do Brasil, 1983) ${ }^{7}$, sobre o jogador de futebol Mané Garrincha, Drummond aponta sua atenção ao comportamento do brasileiro em frente dos problemas do país, embotada pela atenção ao futebol.

\section{Mané e o sonho}

A necessidade brasileira de esquecer os problemas agudos do país, difíceis de encarar, ou pelo menos de suavizá-los com uma cota de despreocupação e alegria, fez com que o futebol se tornasse a felicidade do povo. Pobres e ricos param de pensar para se encantar com ele. E os grandes jogadores convertem-se numa espécie de irmão da gente, que detestamos ou amamos na medida em que nos frustram ou nos proporcionam o prazer de um espetáculo de 90 minutos, prolongado indefinidamente nas conversas e mesmo na solidão da lembrança.

Mané Garrincha foi um desses ídolos providenciais com que o acaso veio ao encontro das massas populares e até dos figurões responsáveis periódicos pela sorte do Brasil, ofertando-lhes o jogador que contrariava todos os princípios sacramentais do jogo, e que, no entanto, alcançava os mais deliciosos resultados.

(...) Se há um deus que regula o futebol esse deus é, sobretudo, irônico e farsante, e Garrincha foi um de seus delegados incumbidos de zombar de tudo e de todos, nos estádios. Mas como é também um deus cruel, tirou do estonteante Garrincha a faculdade de perceber sua condição de agente divino. Foi um pobre e pequeno mortal que ajudou um país inteiro a sublimar suas tristezas. O pior é que as tristezas voltam, e não há outro Garrincha disponível. Precisa-se de um novo que nos alimente o sonho.

Jornal do Brasil, 22/01/1983.

\footnotetext{
${ }^{7}$ Publicada no Jornal do Brasil, em 22 de janeiro de 1983, apenas três dias após a morte do jogador.
} 

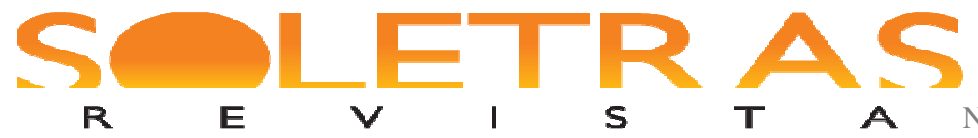

A permanente atenção ao seu tempo constitui uma marca do Drummond político, no mais das vezes escondido na condição de funcionário público, mas vivo em textos e depoimentos. Podemos apontar as anotações em seu diário, no dia do AI-5, decretado pelo governo militar, em dezembro de 1968. Outro dado está de denúncia e resistência está presente na crônica sobre os Yanomami (23/02/1980) e, ainda, em outra publicação na forma de poesia, em que Drummond contesta a destruição do Salto de Sete Quedas para a construção da hidrelétrica de Itaipu Binacional (Jornal do Brasil, Caderno 2, 09/09/1982). Vejamos:

\section{O Yanomami sem Sorte ${ }^{8}$}

Sábado, 23 de fevereiro de 1980.

Se eu fosse yanomami não estaria hoje muito tranqüilo. A boa notícia de que a Funai começará dentro de 90 dias a fazer a demarcação das terras do Parque Indígena onde minha tribo terá direito a viver sua vida me faria um yanomami eufórico. Mas euforia de yanomami dura pouco. Vem a galope uma notícia assustadora. Antes de demarcado a área do Parque já se pensa em reduzi-la, para permitir a exploração de minérios em nosso território. A Funai já negocia mesmo essa redução perante os defensores do Parque íntegro como foi planejado e convém ao interesse dos brasileiros de sangue índio. Então o Parque não será o Parque, mas terra dividida e lacerada de conflitos, como até aqui toda a porção de solo brasileiro em que nós índios somos impedidos de existir à nossa maneira, cedendo espaço e recursos naturais à cobiça de indivíduos e empresas, às vezes nem sequer brasileiras. (...)

\section{Adeus a Sete Quedas}

Sete damas por mim passaram,

E todas sete me beijaram.

Alphonsus de Guimaraens

Aqui outrora retumbaram hinos.

Raimundo Correia

Sete quedas por mim passaram,

e todas sete se esvaíram.

Cessa o estrondo das cachoeiras, e com ele

a memória dos índios, pulverizada,

já não desperta o mínimo arrepio.

Aos mortos espanhóis, aos mortos bandeirantes,

aos apagados fogos

de Ciudad Real de Guaira vão juntar-se

os sete fantasmas das águas assassinadas por mão do homem, dono do planeta.

Aqui outrora retumbaram vozes

\footnotetext{
${ }^{8}$ N. d. E.: Foi respeitada a grafia dos originais, anterior, portanto, à ultima reforma ortográfica.
} 


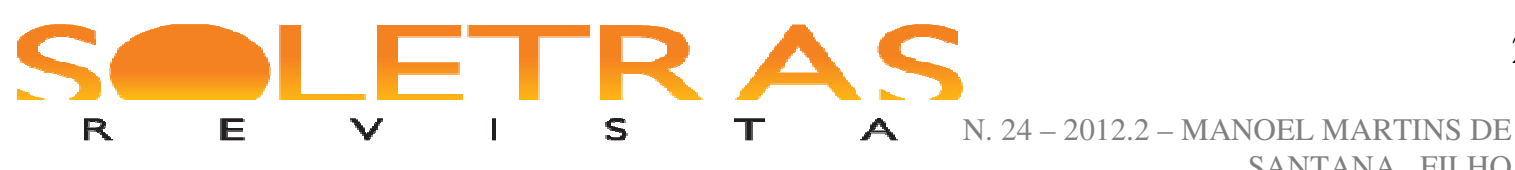

da natureza imaginosa, fértil

em teatrais encenações de sonhos

aos homens ofertadas em contrato.

Uma beleza-em-si, fantástico desenho

Corporizado em cachões e bulcões de aéreo contorno

mostrava-se, despia-se, doava-se

em livre coito à humana vista extasiada.

Toda a arquitetura, toda a engenharia [SEGUE]

de remotos egípcios e assírios

em vão ousaria criar tal monumento.

(...)

Sete quedas por nós passaram,

e não soubemos, ah, não soubemos amá-las,

e todas sete foram mortas,

e todas sete comem no ar,

sete fantasmas, sete crimes

dos vivos golpeando a vida

que nunca mais renascerá.

Há dois outros textos interessantes sobre o tema da guerra: Educação em face da Guerra

(palestra radiofônica de 1942) e Carta a Stalingrado, de 1943:

\section{A Educação em Face da Guerra}

Convidaram-me a falar sobre a educação em face da guerra. Eis aí um grave problema. Antes de mais nada, os dois termos parecem repelir-se. Uma educação ideal importaria na eliminação da guerra como meio solução do choque de interesses entre os homens. Uma guerra total, por sua vez, importaria no fim do trabalho educativo do homem. Entretanto, paradoxalmente, vemos que educação e guerra também se conciliam e que há mesmo, elaborada pelos regimes fascistas, uma "educação para a guerra", monstruosa, implacável, como também, por outro lado, a guerra introduz nos sistemas normais de educação câmbios violentos e profundos.

Dessa educação para a guerra seria pouco todo o mal que se dissesse. A criança submetida a um treinamento moral e psicológico para o ódio é, sem Dúvida, o mais triste exemplar humano.

(...) Cultivemos o nosso jardim, e que esse jardim seja espaçoso e nele caibam todas as espécies dignas de ser contempladas, como todos os encantos se dirigem ao melhor da sensibilidade e da nossa inteligência. Não deixemos que o animal feroz do nazismo invada esse horto sereno. Eis aí, em linguagem figurada, mas que pode ser facilmente transcrita para termos reais, o dever que incumbe hoje, primacialmente ao educador. Mesmo não pegando em armas ele pode trazer contribuição inestimável à luta que todos os países livres hoje desenvolvem contra os países de rapina e destruição. Que o educador prepare homens livres, e a liberdade reinará no mundo.(Grifos nossos)

Carlos Drummond de Andrade 

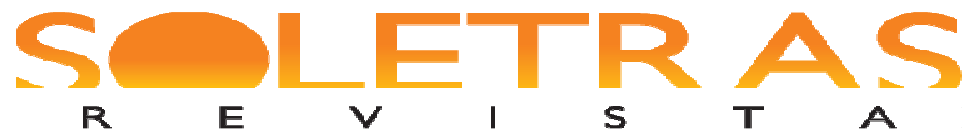

Ainda sobre o tema da natureza e dos homens, vale ressaltar a presença do minério de ferro das serras de Minas e a presença de Itabira, a exploração do Morro do Cauê como uma lembrança permanente na escrita de Drummond. Minas Gerais, seus minérios, suas cidades, suas gentes, seus ritmos cotidianos e sua política são elementos vivos e expressão daquelas paisagens na literatura drummondiana.

(d) O homem classificador e a preocupação com a memória. Evitar o desaparecimento da experiência cultural.

Dessa ideia, encantou-nos a possibilidade de dialogar, a partir do texto do Drummond, sobre a preservação da memória, sobre a condição humana na história e na perspectiva de ele ver o mundo. Os estudiosos sobre o autor, bem como a organização do seu acervo pessoal que se encontra no Arquivo Museu da Literatura Brasileira ${ }^{9}$, mostram-nos um Drummond extremamente cuidadoso com os registros, com a organização da memória que contém a história por ele vivida.

\section{Drummond e a espacialidade do mundo}

Desse lugar de um geógrafo leitor de Drummond, instigou-nos propor atenção àqueles aspectos que, pela intervenção que a literatura faz, ela mesma, no cotidiano das pessoas, promovem a percepção de um onde, de um lugar, de uma paisagem, dos trajetos. Ou seja, de elementos da espacialidade do mundo.

Uma primeira ideia presente é que o texto literário tem em si um potencial formativo que promove e desenvolve, em nós, pensamentos e uma cognição que, de certa forma, chega às nossas ações. Cabe-nos promover esse potencial para além da educação escolar.

O outro aspecto é que determinados autores, como Drummond, fazem esta contribuição de maneira sui generis, favorecendo-nos discutir a geograficidade do nosso cotidiano, sendo este um elemento para nossa educação geográfica. Um debate caro aos geógrafos é aquele que discorre sobre como o saber geográfico resulta de certa capacidade e condição para formular ou apresentar a percepção e a representação do espaço. Percepção e representação são bem

\footnotetext{
${ }^{9}$ O Arquivo Museu da Literatura Brasileira, AMLB, localizado na Fundação Casa de Rui Barbosa no Rio de Janeiro, foi criado por inspiração do própria Drummond. "Foi numa crônica publicada em julho de 1972 que Drummond se referiu à sua "velha fantasia": um museu de literatura que reunisse não só papéis, mas também objetos relacionados à criação e à vida dos escritores brasileiros. Naquele mesmo ano, graças ao poeta e ao bibliófilo Plínio Doyle, nascia o AMLB, cujo acervo se enriqueceu com doações" (AMBL) de diversos materiais pertencentes a dezenas de escritores.
} 

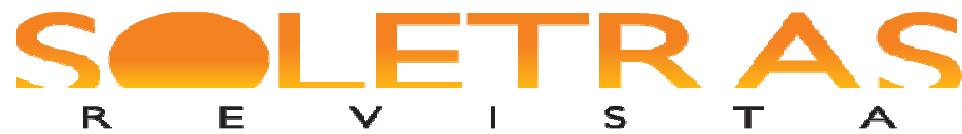

$\mathbf{E}$

$S$

$\mathbf{T}$

N. 24 - 2012.2 - MANOEL MARTINS DE

SANTANA FILHO

apresentadas por um geógrafo colombiano (RODRIGUES, 2010) com quem vimos dialogando nessa perspectiva da Geografia e da Literatura, quando ele explora a importância da cultura para a produção de nossa geografia ${ }^{10}$, enfim, de nossa educação geográfica. Donde concluímos: os registros dessa vida vivida por Drummond e retratada em seus textos, a sua experiência espacial, são elementos que nos educam e habilitam para ler o mundo, o trabalho, suas paisagens, seus homens e mulheres - esse anima pulsante.

A última é uma inspiração permanente como educador, provocado pelo texto de Walter Benjamin (1993) e que diz respeito à promoção da capacidade de ler, de narrar o mundo contemporâneo e insistir na necessidade de nossa autoria. Essa inspiração, essa insistência, diz respeito tanto aos desafios formativos tão presentes para nós, formadores de professores, como também para as condições docentes nas escolas de educação fundamental. No diálogo geoliterário, promover a leitura do texto e do mundo como exigência freireana e promover a capacidade de autoria do cidadão comum é fundamental, permitindo a ele, como sujeito histórico que registre permanências, trânsitos, moradas.

\section{Referências bibliográficas:}

BENJAMIN, Walter. Magia e técnica, arte e política: Obras escolhidas, v. 1. 5. ed. São Paulo: Brasiliense. 1993.

BRAIT, Beth. Literatura e outras linguagens. São Paulo: Contexto. 2010.

CASTELLAR, Sonia M. V.; VILHENA, Jerusa. Ensino de Geografia. São Paulo: Cengage Learning, 2010.

CAVALCANTI, L. S.. A educação geográfica e a formação de conceitos: a importância do lugar no ensino de Geografia. In: GARRIDO, Marcelo (Org.). La espesura del lugar: reflexiones sobre el espacio en el mundo educativo. Santiago de Chile: Universidad Academia del Humanismo Cristiano, 2009, p. 134-152.

FREIRE, Paulo. Pedagogia da Autonomia. São Paulo: Paz e Terra, 1996.

FERRAZ, Eucanaã. O livro em seu tempo: Alguma Poesia, de Carlos Drummond de Andrade. Organização de Eucanaã Ferraz. Rio de Janeiro: Instituto Moreira Salles. 2010.

GENS, Rosa et al. Almanaque Drummond, testemunho da experiência humana. Brasília, DF: ABRAVIDEO, 2011.

\footnotetext{
${ }^{10} \mathrm{O}$ texto citado está disponível em Geopaideia, nas publicações da REDLADGEO: http://www.geopaideia.com/publicaciones/Itinerarios_geograficos.pdf
} 

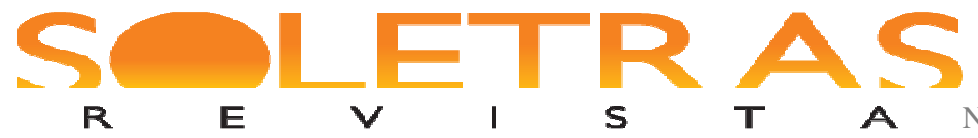

KOCH. Ingedore V. O texto e a construção de sentidos. São Paulo: Contexto, 2001.

LAJOLO, Marisa. O que é literatura. 17. ed. São Paulo: Brasiliense, 1995.

PENNA, João Camillo. Drummond: testemunho da experiência humana. Brasília, DF: ABRAVIDEO, 2011.

RODRIGUES, Alexander C.; BARRERA, Carlos A. Z. El espacio y la cultura como escenarios de aprendizaje de la geografia. In: LACHE, Nubia M; BELTRÁN, Mario F. H. Itinerarios geográficos en la escuela. Bogotá: Geopaideia, 2010.

SANTOS, Milton. Pensando o espaço do homem. 4. ed. São Paulo: Hucitec, 1997.

VIGOTSKI, Lev Semenovich. A construção do pensamento e da linguagem. São Paulo: Martins Fontes, 2009.

\title{
Outras referências bibliográficas no ambiente virtual:
}

http://www.jornaldepoesia.jor.br/anton.html\#sinopse, acessado em dezembro de 2012.

http://www.tanto.com.br/Patativa.htm, acessado em dezembro de 2012.

http://www.casaruibarbosa.gov.br/interna.php?ID_S=15\&ID_M=8, acessado em outubro de 2012.

\section{Knowing geographical spaces with Carlos Drummond de Andrade}

\begin{abstract}
This article introduces an experience that reveals the potential and the deep possibilities that are born from the dialogs between geography and literature. Dialogs that promote readings, cognition and representation of the world and its geographicity. The works of Carlos Drummond de Andrade explore some of the tracks that reveal the geography of the literary text and the literature inspiring such geography. The reading of those exemplified texts in the related experience present us some visions of human experience about daily life, about memory, about urban, rural, history, memory and culture. Finally, it is intended that these geoliterary dialogs produce a geographical education that enables students and the contemporary man to develop conditions of authorship and expression.
\end{abstract}

Key words: Geography. Literature. Geographic education. Carlos Drummond de Andrade.

Recebido em: 28 de dezembro de 2012.

Aprovado em: 03 de fevereiro de 2013. 